\title{
PENGARUH INDEPENDENSI DAN PROFESIONALISME, DALAM MENDETEKSI FRAUD PADA AUDITOR INTERNAL PROVINSI SULAWESI UTARA
}

\author{
Herman karamoy \\ Heince R.N. Wokas
}

(email : hkaramoy@yahoo.com)

\begin{abstract}
This study to examine the influence of independency and professionalism, to detects fraud, at Accountant internal in Sulawesi Utara. This study used convenience sampling method, and the sampling of this research are 40 auditor internal in 4 Inspektorat of regency and city. The data were collected through questions survey methods. The analysis technique's multiple regression.

From the analyst there found partially professionalism, significant influence on detects fraud. While the independency partial no significant effect on detects fraud.
\end{abstract}

Keywords: Professionalism, detects errors, experienced, profession ethics, materiality levels

\section{PENDAHULUAN}

Auditor bertanggung jawab memberikan jaminan dan penilaian terhadap laporan keuangan yang disajikan oleh sebuah institusi keuangan, apakah telah disajikan secara wajar dan dapat dipercaya atau tidak. Informasi tentang kinerja suatu perusahaan sangat tergantung pada hasil penilaian akuntan publik. Kata "wajar tanpa pengecualian", yang menjadi pendapat akuntan publik, mengandung makna bahwa informasi yang diauditnya layak dipercaya, tidak mengandung keragu-raguan. Karena itu dalam menjalankan audit, akuntan bertanggung jawab mendeteksi kemungkinan kekeliruan yang materiil dan kecurangan (fraud).

Independensi dalam profesi sangat dibutuhkan untuk menjaga kualitas auditor tersebut. Independensi bukan hanya dimiliki oleh auditor eksternal namun juga dimiliki oleh auditor internal. Independensi menurut Mautz dan Sharaf dalam karya terkenal mereka, "The Philosophy of Auditing" (Filosofi Audit), (Sawyer, 2006:35) terbagi menjadi 3 yaitu: independensi dalam verifikasi, independensi dalam program audit, dan independensi dalam pelaporan yang dapat diperuntukkan bagi akuntan publik atau auditor eksternal, tetapi konsep yang sama dapat diterapkan untuk auditor internal dalam bersikap objektif. Independensi dalam hal ini adalah independensi dalam pelaporan dimana menurut Sawyer (2006:36) independensi dalam pelaporan menjadikan auditor internal: harus bebas dari perasaan untuk memodifikasi dampak dari fakta-fakta, harus bebas dari hambatan oleh pihak-pihak yang ingin meniadakan auditor dalam memberikan pertimbangan.

Selain itu profesionalisme juga menjadi syarat utama bagi seseorang yang ingin menjadi seorang auditor sebab dengan profesionalisme yang tinggi kebebasan auditor akan semakin terjamin. Untuk menjalankan perannya yang menuntut tanggung jawab yang semakin luas, seorang auditor harus memiliki wawasan yang luas tentang kompleksitas organisasi modern. Gambaran tentang profesionalisme seorang auditor menurut Hall (1968) dalam Wahyudi (2006), tercermin dalam lima hal yaitu: pengabdian dalam profesi, kewajiban sosial, kemandirian, kepercayaan terhadap peraturan profesi, dan hubungan dengan rekan seprofesi. Setiap auditor internal harus tetap mempertahankan independensinya serta profesionalismenya agar dapat mendeteksi segala bentuk tindak kecurangan (fraud) yang terjadi. Berdasarkan uraian diatas, maka peneliti bermaksud menguji Pengaruh Independensi dan Profesionalisme Auditor Internal Dalam Mendeteksi Fraud pada Pemerintah Daerah Provinsi Sulawesi Utara. Tujuan penelitian ini untuk mengetahui Pengaruh Independensi dan Profesionalisme Auditor Internal Dalam Mendeteksi Fraud pada Pemerintah Daerah Provinsi Sulawesi Utara

\section{TINJUAN PUSTAKA}

Menurut SPAP seksi 220, menyatakan bahwa independensi diartikan "sebagai tidak mudah dimengerti". Sedangkan Mulyadi (2006) adalah sebagai berikut : "Independensi berarti bersikap bebas 
dari pengaruh pihak lain, tidak tergantung pada pihak lain dan jujur dalam mempertimbangkan fakta serta adanya pertimbangan yang objective dalam merumuskan dan menyatakan pendapatnya." Arens dan Loebbeck (2009) menyatakan independensi merupakan tujuan yang harus selalu diupayakan, dan itu dapat dicapai sampai tingkat tertentu, misalnya sekalipun auditor dibayar oleh klien, ia harus tetap memiliki kebebasan yang cukup untuk melakukan audit yang andal. Sedangkan Ralph Estes menyatakan pendapat mengenai independensi adalah sebagai kondisi keterbukaan, netral dan tidak bias, untuk atau terhadap pihak lain.

Dalam buku Standar Profesi Akuntan Publik (SPAP, 2009) seksi 220 PSA No.04 alinea 2, dijelaskan bahwa: "Independensi berarti tidak mudah dipengaruhi, karena ia melaksanakan pekerjaannya untuk kepentingan umum." Dengan demikian, ia tidak dibenarkan memihak kepada kepentingan siapapun meskipun ia bekerja atau mengabdi pada perusahaan, sebab bilamana tidak demikian halnya, bagaimanapun sempurnanya keahlian teknis yang ia miliki, maka dengan otomatis ia akan kehilangan sikap independensi yang justru paling penting untuk mempertahankan kebebasan pendapatnya.

Auditor internal yang profesional harus memiliki independensi untuk memenuhi kewajiban profesionalnya; memberikan opini yang objektif, tidak bias, dan tidak dibatasi; dan melaporkan masalah apa adanya, bukan melaporkan sesuai keinginan eksekutif atau lembaga (Sawyer: 2006:35). Untuk mengetahui apakah seorang auditor internal telah profesional dalam melakukan tugasnya, maka perlu adanya evaluasi kinerja. Dan evaluasi kinerja auditor internal dapat dilakukan dengan cara yaitu: sudahkah terpenuhinya kriteria-kriteria profesionalisme auditor internal.

Menurut Arens dan Loebbecke (2009) berpendapat bahwa untuk meningkatkan profesionalisme, sering akuntan harus memperlihatkan perilaku profesinya, yang berupa:

a. Tanggung jawab Dalam melaksanakan tanggung jawabnya sebagai profesional, akuntan harus mewujudkan kepekaan profesional dan pertimbangan moral dalam semua aktivitas mereka.

b. Kepentingan masyarakat Akuntan harus menerima kewajiban untuk melakukan tindakan yang mendahulukan kepentingan masyarakat, menghargai kepercayaan masyarakat, dan menunjukkan komitmen pada profesionalisme.

c. Integritas Untuk mempertahankan dan memperluas kepercayaan masyarakat, akuntan harus melaksanakan semua tanggung jawab profesional dengan integritas tertinggi.

d. Objektivitas dan Independensi Akuntan harus mempertahankan objektivitas dan bebas dari benturan kepentingan dalam melakukan tanggung jawab profesional.

e. Keseksamaan

Akuntan harus memenuhi standar teknis dan etika profesi, berusaha keras untuk terus meningkatkan kompetensi dan mutu jasa dan melakukan tanggung jawab profesional dengan kemampuan terbaik.

f. Lingkup dan Sifat Jasa Dalam menjalankan praktik sebagai akuntan publik, akuntan harus mematuhi prinsip-prinsip perilaku profesional dalam menentukan lingkup dan jasa audit yang akan diberikan.

\section{Kecurangan (Fraud)}

Ikatan Akuntan Indonesia (IAI) Ikatan Akuntan Indonesia (IAI) dalam Standar Profesional Akuntan Publik (SPAP) memberikan definisi tentang kekeliruan dan ketidakberesan sebagai berikut ini (IAI, 2009:316.2\&3). Kekeliruan (error) berarti salah saji (misstatement) atau hilangnya jumlah atau pengungkapan dalam laporan keuangan yang tidak sengaja.

Ketidakberesan (irregularities) adalah salah saji atau hilangnya jumlah pengungkapan dalam laporan keuangan yang dilakukan untuk menyajikan laporan keungan yang menyesatkan, dan seringkali disebut dengan kecurangan manajemen, serta penyalahgunaan aktiva yang seringkali disebut dengan unsur penggelapan.

Meskipun demikian pada dasarnya Fraud adalah merupakan serangkaian ketidakberesan (irregularities) mengenai: perbuatan-perbuatan melawan hukum (illegal acts), yang dilakukan dengan sengaja untuk tujuan tertentu (misalnya menipu memberikan gambaran yang keliru (mislead) terhadap pihak lain), yang dilakukan oleh orang-orang dari dalam ataupun dari luar organisasi, untuk mendapatkan keuntungan baik pribadi maupun kelompok dan secara langsung atau tidak langsung merugikan orang lain.

Mendeteksi Terjadinya Fraud 
Kurangnya pengetahuan auditor internal dan pemahaman atas fraud sering terjadi dan prosedur yang efektif untuk mendeteksi penipuan membuat seorang auditor internal kesulitan melakukan tugasnya. Masing-masing jenis kecurangan memiliki karakteristik tersendiri, sehingga untuk dapat mendeteksi kecurangan yang mungkin timbul dalam perusahaan sedikit sulit. Sebagian besar bukti-bukti kecurangan merupakan bukti-bukti yang sifatnya tidak langsung.

Petunjuk adanya kecurangan (fraud) biasanya ditunjukkan oleh munculnya gejala-gejala (symptoms) misalnya, adanya perubahan gaya hidup atau perilaku seseorang, dokumentasi yang mencurigakan, keluhan dari pelanggan ataupun kecurigaan dari rekan sekerja. Karekteristik yang bersifat kondisi atau situasi tertentu, perilaku atau kondisi seseorang personal tersebut dinamakan Red Flag (Fraud Indicators). Timbulnya red flag ini biasanya selalu muncul di setiap kasus kecurangan yang terjadi. Peyimpangan fisik properti, akses ke catatan akuntansi, dan pengetahuan atau otoritas untuk menolak pengendalian adalah kandungan utama dari kecurangan dalam buku besar dan laporan keuangan.

\section{Kerangka Penelitian}

Dari kerangka pemikiran dapat digambarkan model penelitiannya sebagai berikut:

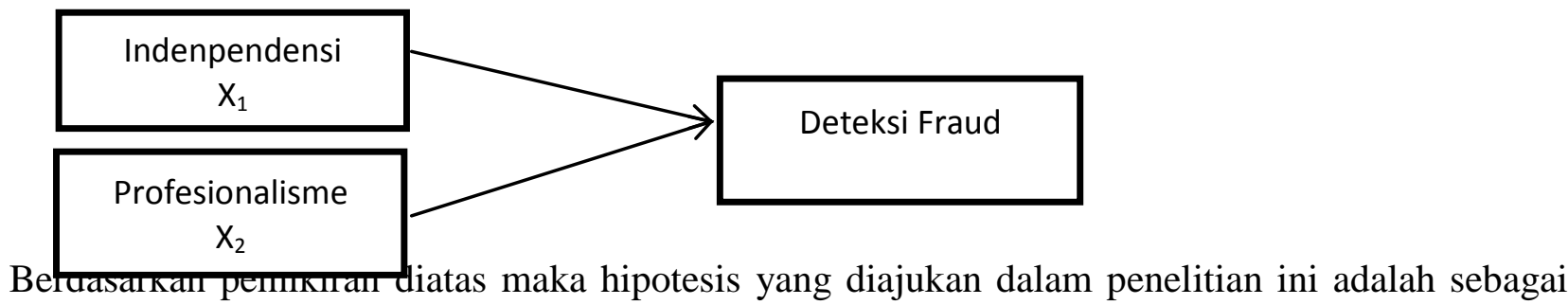

berikut:

Ha1 : Terdapat pengaruh yang signifikan independensi auditor internal dalam mendeteksi fraud.

Ha2 : Terdapat pengaruh yang signifikan profesionalisme auditor internal dalam mendeteksi fraud.

Ha3 : Terdapat pengaruh yang signifikan independensi auditor internal dan profesionalisme auditor internal secara simultan (bersama-sama) dalam mendeteksi fraud.

\section{METODE PENELITIAN}

Penelitian ini bertujuan untuk menguji hipotesa yang berupa hubungan atau pengaruh antar variabel. Di dalam penelitian ini hubungan atau pengaruh yang diteliti meliputi Independensi dan Profesionalisme Auditor Internal Dalam Mendeteksi Fraud pada Pemerintah Daerah Provinsi Sulawesi Utara. Populasi dalam penelitian ini adalah semua Pegawai Negeri Sipil (PNS) yang bekerja pada Inspektorat di provinsi Sulawesi Utara Tehnik pengambilan sampel dilakukan dengan pendekatan convenience sampling yang menjadi sampel adalah Inspektorat Kabupaten Talaud, Inspektorat Kota Kotamobagu, Inspektorat Kota Manado, dan Inspektorat Provinsi Sulawesi Utara untuk menentukan sampel dari populasi yang memenuhi kriteria tertentu sesuai yang penulis kehendaki, yaitu yang sudah mengikuti pendidikan dan pelatihan (diklat) sebagai auditor.

Metode pengambilan data yang digunakan adalah survey method. Data yang digunakan dalam penelitian ini adalah data primer, yaitu data diperoleh melalui kuesioner yang langsung disebarkan kepada Auditor dan staf pemeriksa yang bekerja pada Inspektorat tingkat kota/kabupaten atau Bawasda di lingkungan pemerintah daerah kabupaten/kota Provinsi Sulawesi Utara. Setiap jawaban dari pernyataan dalam kuisioner tersebut telah ditentukan skornya berdasarkan skala Likert 5 poin.

\section{Variabel Penelitian dan Definisi Operasional Variabel}

Penelitian ini akan menguji pengaruh variabel independen yang terdiri dari Independensi dan Profesionalisme terhadap variabel dependen yaitu Deteksi Audit. Definisi operasional dan pengukuran untuk variabel-variabel tersebut adalah:

a. Independensi Auditor Internal Independensi berarti bersikap bebas dari pengaruh pihak lain, tidak tergantung pada pihak lain dan jujur dalam mempertimbangkan fakta serta adanya pertimbangan yang objective dalam merumuskan dan menyatakan pendapatnya (Mulyadi, 2006).

b. Profesionalisme Auditor Internal Profesionalisme adalah perilaku yang diharapkan pada seseorang di tingkat tertinggi dari anggota suatu perkumpulan (Arens dan Loebbecke,2009:74). 
c. Variabel Dependen dalam penelitian ini adalah mendeteksi terjadinya fraud. Kecurangan (Fraud) meliputi serangkaian ketidakbiasaan dan atau tindakan ilegal yang bercirikan penipuan yang disengaja. Kecurangan dapat dilakukan untuk kepentingan atau atas kerugian organisasi dan oleh orang di luar atau di dalam organisasi (Prasetyo,2002).

\section{Metode Analisis Data.}

Metode analisis untuk pengujian hipotesis dalam penelitian ini menggunakan analisis regresi berganda dengan bantuan software SPSS 20.0, dengan $\alpha=5 \%$. Persamaan yang digunakan adalah :

$$
\begin{array}{cl}
\mathbf{Y}=\mathbf{a}+\mathbf{b} 1 \mathbf{X} 1 & +\mathbf{b} \mathbf{2 X} \mathbf{2}+\mathbf{e} \\
\multicolumn{1}{|c|}{\text { Keterangan: }} \\
\mathrm{Y} & =\text { Mendeteksi Fraud } \\
\mathrm{a} & =\text { Konstanta } \\
\mathrm{b} 1 \mathrm{~b} 2 & =\text { Koefisien } \\
\mathrm{X} 1 & =\text { Independensi } \\
\mathrm{X} 2 & =\text { Profesionalisme } \\
\mathrm{e} & \text { error terms }
\end{array}
$$

Agar model regresi dapat menghasilkan estimator yang baik (Best Linier Unbiased Estimator)

\section{HASIL DAN PEMBAHASAN}

Berdasarkan identitas responden, karakteristik responden dapat dikelompokkan berdasarkan jenis kelamin, umur, tingkat pendidikan, dan lama bekerja sebagai auditor secara umum dalam penelitian ini dapat diketahui hal-hal sebagai berikut:

\begin{tabular}{|l|l|l|}
\hline KETERANGAN & RESPONDEN & PROSENTASI \\
\hline A. JENIS KELAMIN & & \\
- Laki-Laki & 22 Orang & $55 \%$ \\
- Perempuan & 18 Orang & $45 \%$ \\
\hline B. UMUR & & \\
- 20-25 Tahun & 12 Orang & $30 \%$ \\
- 29-31 Tahun & 18 Orang & $45 \%$ \\
- - > 31 Tahun & 10 Orang & $25 \%$ \\
\hline C. PENDIDIKAN & & \\
- Diploma & 3 Orang & $7,5 \%$ \\
- S1 & 35 Orang & $87,5 \%$ \\
- S2 & 2 Orang & $5 \%$ \\
- S3 & - & $0 \%$ \\
\hline D. LAMA BEKERJA & 8 Orang & $20 \%$ \\
- <1 Tahun & 20 Orang & $50 \%$ \\
- 1 - 3 Tahun & 9 Orang & $22,5 \%$ \\
- 3 - 10 Tahun & 3 Orang & $7,5 \%$ \\
\hline
\end{tabular}

a. Berdasarkan jenis kelamin, 22 orang $(55 \%)$ berjenis kelamin wanita, dan sisanya sebanyak 18 orang (45\%) berjenis kelamin pria. Dapat dilihat bahwa pada penelitian ini, lebih banyak auditor wanita daripada auditor pria. b). Berdasarkan umur, auditor paling banyak berumur antara 20-25 tahun yaitu sebanyak 12 orang (30\%). Sedangkan auditor yang berumur antara 29-31 tahun sebanyak 18 orang (45\%) dan $>31$ tahun sebanyak 10 orang $(25 \%)$. c). Berdasarkan tingkat pendidikan, auditor yang memiliki pendidikan Strata 1 sebanyak 35 orang $(87,5 \%)$ lebih banyak dibandingkan auditor yang memiliki pendidikan Strata 2 sebanyak 2 orang (5\%) ataupun Diploma 3 sebanyak 3 orang (7,5\%) dan Strata 3 sebanyak 0\%. d)Berdasarkan lama bekerja sebagai auditor, akuntan publik dengan pengalaman kerja antara $<1$ tahun sebanyak 8 orang (20\%), sedangkan pengalaman kerja antara 1-3 tahun paling mendominasi responden penelitian ini yaitu sebanyak 20 orang (50\%), pengalaman kerja antara 3-10 tahun sebanyak 9 orang (22,5\%), dan pengalaman kerja antara $>10$ tahun sebanyak 3 orang $(7,5 \%)$. Untuk memperoleh hasil regresi linier yang baik maka digunakan uji asumsi klasik, yaitu: 


\section{Uji Heteroskedastisitas}

Untuk mendeteksi ada tidaknya heteroskedastisitas, dapat dilakukan dengan melihat ada atau tidaknya pola tertentu pada grafik Scatter Plot.

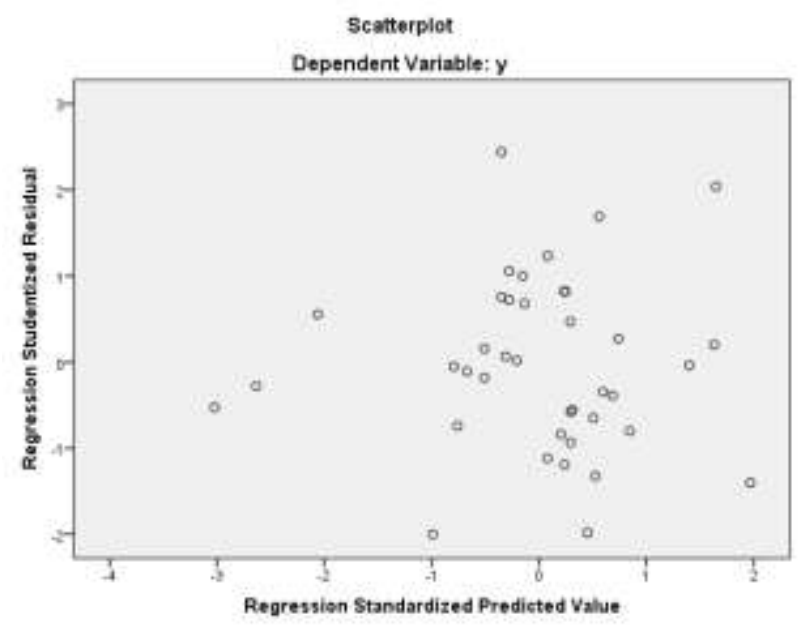

Sumber : Output Pengolahan Data SPSS, 2015

Dari Gambar tersebut di atas nampak bahwa diagram pencar residual tidak membentuk suatu pola tertentu atau posisinya dalam keadaan menyebar. Kesimpulannya, model regresi terbebas dari kasus heteroskedastisitas dan memenuhi persyaratan asumsi klasik tentang heteroskedastisitas.

\section{a. Uji Multikolinearitas}

Mendeteksi ada tidaknya multikolinearitas yaitu dengan menganalisis Variance Inflation Factor (VIF). Nilai VIF yang bisa ditoleransi adalah 10. Apabila nilai VIF variabel bebas $<10$, berarti tidak ada multikolinearitas. Berdasarkan hasil perhitungan dengan menggunakan bantuan program SPSS seperti yang ada pada Lampiran 4, untuk pengujian asumsi klasik multikolinearitas dapat dilihat dalam Tabel berikut,

Sumber : Output Pengolahan Data SPSS, 2015

Uji Multikolinearitas

\begin{tabular}{|ll|l|l|}
\hline \multicolumn{2}{|l|}{ Model } & \multicolumn{2}{|l|}{ Collinearity Statistics } \\
\cline { 3 - 4 } & & Tolerance & VIF \\
\hline \multirow{3}{*}{1} & (Constant) & & \\
& $\mathrm{x} 1$ & 949 & 1.054 \\
& $\mathrm{x} 2$ & .949 & 1.054 \\
\hline
\end{tabular}

Dari Tabel 4.5 nilai VIF untuk $\mathrm{X}_{1}$ menunjukkan angka sebesar 1,054; dan $\mathrm{X}_{2}$ sebesar 1,054 maka dapat disimpulkan bahwa tidak terjadi multikolinearitas dalam model regresi karena semua nilai VIF yang dihasilkan oleh Variabel $\mathrm{X}_{1}$, dan $\mathrm{X}_{2},<10$.

\section{b. Uji Asumsi Klasik Autokorelasi}

Autokorelasi adalah korelasi antara sesama urutan pengamatan dari waktu ke waktu. Untuk memeriksa adanya autokorelasi, biasanya memakai uji Durbin Watson $(D W)$ dengan kriteria keputusan sebagai berikut :

- Jika DW < 1,21 atau DW > 2,79 maka terjadi autokorelasi.

- Jika 1,65 < DW < 2,35 maka tidak terjadi autokorelasi.

- Jika 2,35 < DW < 2,79 maka autokorelasi tidak dapat disimpulkan.

Berdasarkan hasil perhitungan dengan menggunakan bantuan Program SPSS seperti yang ada pada Lampiran untuk pengujian asumsi klasik autokorelasi dapat dilihat dalam Tabel berikut ini

\begin{tabular}{|l|r|r|}
\hline Model & \multicolumn{1}{|c|}{$\mathrm{R}$} & Durbin-Watson \\
\hline 1 & $.417^{\mathrm{a}}$ & 1.569 \\
\hline
\end{tabular}

Sumber : Output Pengolahan Data SPSS, 2015 
Dari Tabel tersebut dapat dilihat bahwa nilai Durbin Watson (DW) sebesar 1,569 atau menunjukkan bahwa nilai DW $<1,21$ dan $>2,79$ maka dapat disimpulkan bahwa tidak terjadi autokorelasi dalam model regresi.

\section{c. Uji Normalitas}

Tujuan dilakukannya uji asumsi normalitas adalah untuk menguji apakah dalam sebuah model regresi, variabel bebas dan variabel terikat mempunyai distribusi normal atau tidak. Model regresi yang baik adalah distribusi data normal atau mendekati normal. Dasar pengambilan keputusan adalah jika data menyebar disekitar garis diagonal dan mengikuti arah garis diagonal, maka memenuhi persyaratan asumsi normalitas. Berdasarkan hasil perhitungan dengan menggunakan Program SPSS seperti yang ada pada Lampiran, maka Grafik Normalitas dapat dilihat dalam Gambar 4.2.

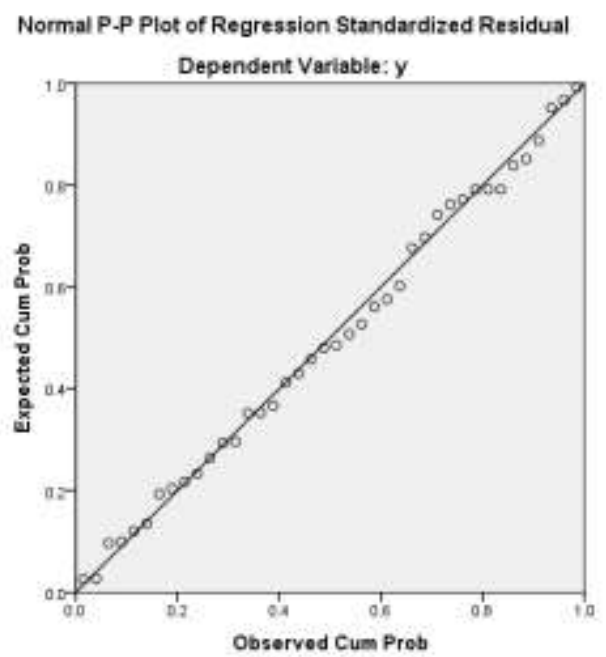

Sumber : Output Pengolahan Data SPSS, 2015

Dari Gambar 4.2 dapat dilihat bahwa data menyebar di sekitar garis diagonal dan mengikuti arah garis diagonal, maka dapat dikatakan bahwa model regresi memenuhi syarat asumsi normalitas.

\section{Regresi Linear Berganda}

Hasil perhitungan analisi regresi linier berganda dapat dilihat dalam tabel berikut

Regresi Linear Berganda

\begin{tabular}{|cc|c|c|c|c|c|}
\hline \multirow{2}{*}{ Model } & \multicolumn{2}{|c|}{ Unstandardized Coefficients } & $\begin{array}{c}\text { Standardized } \\
\text { Coefficients }\end{array}$ & \multirow{2}{*}{$\mathrm{t}$} & Sig. \\
\cline { 3 - 5 } & $\mathrm{B}$ & Std. Error & Beta & & \\
\hline \multirow{2}{*}{1} & (Constant) & 12.087 & 6.811 & & 1.775 & .084 \\
& $\mathrm{x} 1$ & .265 & .140 & .290 & 1.893 & .066 \\
& $\mathrm{x} 2$ & .217 & .089 & .372 & 2.425 & .020 \\
\hline
\end{tabular}

Sumber : Output Pengolahan Data SPSS, 2015

Berdasarkan hasil perhitungan dengan menggunakan bantuan program SPSS seperti pada tabel di 4.7 maka dapat dilihat pada bagian "Coefficient" bahwa model regresi yang diperoleh adalah :

$\mathbf{Y}=\alpha+\beta \mathbf{X}_{1}+\beta \mathbf{X}_{2}+\mathbf{e}$

$Y=12,087+0,265 X_{1}+0,217 X_{2}+e$

Konstanta $(\alpha)$ sebesar 12,087 yang bernilai positif memberikan pengertian bahwa jika variabel Indenpendensi, dan Profesionalisme tidak ada atau sama dengan nol (0), maka kemampuan untuk mendeteksi fraud akan meningkat.

Nilai $\beta_{1}$ yang merupakan koefisien korelasi dari variabel Independensi $\left(\mathrm{X}_{1}\right)$ bernilai positif mempunyai arti bahwa jika variabel Independensi naik, maka variabel dalam mendeteksi fraud akan mengalami kenaikan atau mempunyai hubungan yang searah.

Nilai $\beta_{2}$ yang merupakan koefisien korelasi dari variabel Profesionalisme $\left(\mathrm{X}_{2}\right)$ bernilai positif atau searah mempunyai arti bahwa jika variabel Profesionalisme meningkat, maka variabel dalam mendeteksi Fraud juga akan mengalami kenaikan. 
Dengan demikian dapat diketahui bahwa setiap kali terjadi perubahan variable Indenpendensi, dan Profesionalisme, maka akan mempengaruhi auditor dalam mendeteksi fraud.

\section{Koefisien Korelasi $(\mathbf{R})$}

Analisis koefisien korelasi (R) ini digunakan untuk mengukur keeratan hubungan antara variabel bebas $(\mathrm{X})$ terhadap variabel terikat $(\mathrm{Y})$, dalam hal ini mengukur kuat lemahnya hubungan Independensi $\left(\mathrm{X}_{1}\right)$, Obyektivitas $\left(\mathrm{X}_{2}\right)$, Pengalaman Kerja $\left(\mathrm{X}_{3}\right)$, Pengetahuan $\left(\mathrm{X}_{4}\right)$, dan Integritas $\left(\mathrm{X}_{5}\right)$ dengan Kualitas Hasil Audit (Y).

\begin{tabular}{|c|c|c|c|c|}
\hline \multicolumn{5}{|c|}{ Correlations } \\
\hline \multirow{3}{*}{ Pearson Correlation } & $\mathrm{y}$ & 1.000 & .206 & .306 \\
\cline { 2 - 6 } & $\mathrm{x} 1$ & .206 & 1.000 & -.227 \\
\cline { 2 - 6 } & $\mathrm{x} 2$ & .306 & -.227 & 1.000 \\
\hline
\end{tabular}

Sumber : Output Pengolahan Data SPSS, 2015

Berdasarkan hasil perhitungan dengan menggunakan bantuan program SPSS seperti yang ada pada tabel bagian Correlations dapat dilihat bahwa koefisien korelasi linear yang dihasilkan antara variable Independensi $\left(\mathrm{X}_{1}\right)$ dalam mendeteksi Fraud (Y) adalah sebesar 0,206 atau 20,6 \% artinya tidak memiliki tingkat hubungan yang berlawanan atau negatif dan koefisien korelasi linear yang dihasilkan variabel Profesionalisme $\left(\mathrm{X}_{2}\right)$ dalam mendeteksi fraud $(\mathrm{Y})$ adalah sebesar 0,306 atau 30,6 \% artinya hubungan yang searah atau positif, Maka dapat disimpulkan bahwa kedua variabel Independensi, dan Profesionalisme memiliki hubungan yang lemah karena semua berada dibawah $50 \%$ korelasinya terhadap mendeteksi fraud.

\section{Koefisien Determinan $\left(\mathbf{R}^{2}\right)$}

Koefisien determinasi $\left(\mathrm{R}^{2}\right)$ diperlukan untuk mengukur seberapa besar pengaruh Independensi $\left(\mathrm{X}_{1}\right)$, dan Profesionalisme $\left(\mathrm{X}_{2}\right)$, dalam mendeteksi Fraud $(\mathrm{Y})$, dapat dilihat pada tabel berikut :

\section{Koefisien Determinan}

Model Summary

\begin{tabular}{|c|c|c|c|c|c|}
\hline Model & $\mathrm{R}$ & $\mathrm{R}$ Square & $\begin{array}{c}\text { Adjusted R } \\
\text { Square }\end{array}$ & $\begin{array}{c}\text { Std. Error of the } \\
\text { Estimate }\end{array}$ & Durbin-Watson \\
\hline 1 & $.417^{\mathrm{a}}$ & .174 & .129 & 3.02194 & 1.569 \\
\hline
\end{tabular}

a. Predictors: (Constant), x2, x1

b. Dependent Variable: y

Sumber : Output Pengolahan Data SPSS, 2015

Berdasarkan hasil perhitungan dengan menggunakan bantuan program SPSS seperti nampak pada tabel 4,9, maka dapat diketahui nilai $\mathrm{R}$ Square yang diperoleh adalah sebesar 0,174 atau 17,4\%. Nilai $\mathrm{R}$ Square memberikan pengertian bahwa variable dependen dapat dijelaskan oleh variabel independen yaitu variable Independensi, dan Profesionalisme adalah sebesar 17,4 \% sementara sisanya 82,6 \% dijelaskan oleh variabel lain yang tidak diteliti dalam penelitian ini.

\section{Pengujian Hipotesis}

Perumusan hipotesis yang diuji, telah dikemukakan dalam Bab sebelumnya dengan tingkat signifikansi yang digunakan dalam penelitian ini sebesar $5 \%$ atau $\alpha=0,05$ maka hasil pengujian hipotesis tersebut adalah sebagai berikut :

\section{a. Uji F}

Dengan menggunakan bantuan program SPSS version 20.0 maka hasil $\mathrm{F}_{\text {hitung }}$ dapat dilihat dalam tabel berikut

Uji F

ANOVA $^{\mathrm{a}}$

\begin{tabular}{|c|c|c|c|c|c|}
\hline Model & Sum of Squares & $\mathrm{df}$ & Mean Square & $\mathrm{F}$ & Sig. \\
\hline Regression & 71.087 & 2 & 35.544 & 3.892 & $.029^{b}$ \\
\hline
\end{tabular}




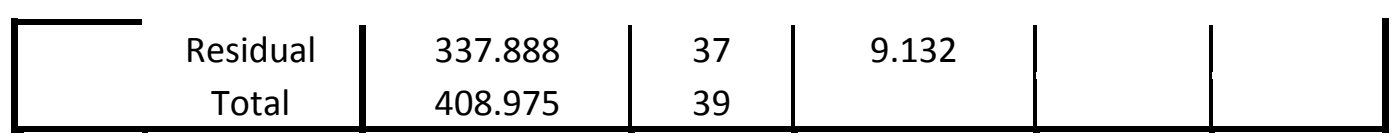

a. Dependent Variable: $y$

b. Predictors: (Constant), x2, x1

Sumber : Output Pengolahan Data SPSS, 2015

Dari Tabel tersebut dapat dilihat uji F Signifikan dimana nilai signifikansi p sebesar $0,029<0,05$ maka dapat disimpulkan bahwa $\mathrm{H}_{0}$ ditolak dan $\mathrm{H}_{\mathrm{a}}$ diterima, yang berarti bahwa Variabel Independensi, dan Profesionalisme secara simultan berpengaruh terhadap Kualitas Hasil Audit.

\section{b. Uji t}

Uji t digunakan untuk menguji signifikansi pengaruh variabel independen terhadap variabel dependen dalam model regresi yang sudah dihasilkan. Maka digunakan uji t untuk menguji masingmasing variabel independen terhadap variabel dependen.

Dari table 4.7 hasil uji t untuk Independensi $\left(\mathrm{X}_{1}\right)$ nilai signifikansi $\mathrm{p}=0,066>0,05$ berarti $\mathrm{H}_{0}$ diterima dan $\mathrm{H}_{\mathrm{a}}$ ditolak artinya variabel Independensi berpengaruh positif tidak signifikan dalam mendeteksi fraud bagi auditor internal di Sulawesi Utara.

Selanjutnya untuk uji t pada variabel Profesionalisme $\left(\mathrm{X}_{2}\right)$ nilai signifikansi p-value $=0,020<$ 0,05 berarti $\mathrm{H}_{0}$ ditolak dan $\mathrm{H}_{a}$ diterima. artinya variabel Profesionalisme berpengaruh positif dan signifikan dalam mendeteksi fraud bagi Auditor Internal di provinsi Sulawesi Utara.

\section{Pengaruh Independensi dalam mendeteksi fraud}

Hasil analisis data dan pengujian hipotesis di atas memperlihatkan bahwa Independensi $\left(\mathrm{X}_{1}\right)$ berpengaruh signifikan dalam mendeteksi fraud (Y) pada auditor internal di Provinsi Sulawesi Utara, Hasil ini tidak konsisten dengan penelitian yang dilakukan oleh Penelitian oleh YunintaSari (2010), Pratiwi dkk.(2015) menemukan bukti empiris bahwa independensi berpengaruh signifikan dalam mendeteksi fraud. Hasil penelitian Trisnaningsih (2007) mengindikasikan bahwa seorang auditor hanya memahami good governance tetapi dalam pelaksanaan pemeriksaan tidak menegakkan independensinya maka tidak akan berpengaruh terhadap kinerjanya. Tidak signifikannya pengaruh independensi terhadap kualitas hasil audit karena adanya instruksi dari atasan untuk tidak mengungkapkan hasil temuan dan memodifikasi hasil temuan tersebut. Sukriah dkk (2009) menemukan adanya praktek - praktek intervensi pimpinan dan usaha-usaha manejerial dari objek pemeriksaan untuk menentukan atau menunjuk kegiatan yang diperiksa, menyebabkan tidak signifikannya pengaruh independensi dalam mendeteksi fraud.

\section{Pengaruh Profesionalisme dalam mendeteksi Fraud}

Hasil analisis data dan pengujian hipotesis, memperlihatkan bahwa Profesionalisme $\left(\mathrm{X}_{2}\right)$ berpengaruh signifikan dan positif dalam mendeteksi Fraud (Y) pada auditor internal di Provinsi Sulawesi Utara, professional auditor berbanding lurus dengan kemampuan seorang auditor dalam mendeteksi fraud. Hasil ini konsisten dengan penelitian yang dilakukan oleh, lestari dan Utama (2013), Pratiwi dkk (2015). Semakin baik Profesionalisme seorang auditor maka semakin banyak baik seorang auditor dalam mendeteksi segala macam kecurangan.

\section{KESIMPULAN DAN SARAN}

Berdasarkan hasil penelitian dan pembahasan maka dapat disimpulkan bahwa dalam mendeteksi kecurangan (Fraud) akan dipengaruhi oleh profesionalisme seorang auditor sedangkan variabel indenpendensi tidak signifikan berpengaruh bagi auditor internal di Inspektorat Sulawesi Utara.

Saran peneliti bagi seorang auditor internal harus lebih meningkatkan profesionalisme dan indenpedensi dalam mendeteksi terjadinya kecurangan (fraud). penelitian ini hanya meneliti 2 variabel, sampel yang digunakan hanya auditor internal pada empat pemerintah daerah di Sulawesi Utara, peneliti selanjutnya hendaknya menambah variable dan sampel penelitian. Penelitian ini menggunakan data primer sehingga kemungkinan pengisian bisa terjadi perbedaan penafsiran, peneliti selanjutnya hendaknya menggunakan juga wawancara (deep interview) sehingga informasi yang didapat lebih akurat dan lengkap. 
Agoes, Soekrisno. “Auditing”. Edisi Ketiga. Jilid 1. Jakarta : Lembaga Penerbit Fakultas Ekonomi Universitas Indonesia.2004. Amrizal. "Pencegahan dan Pendeteksian Kecurangan oleh Internal Audit", 2004.

Arens, Alvin A dan James K. Loebbecke. “Auditing and Assurance Services”, Salemba Empat, Jakarta, 2009.

Boynton, W.C, Johnson, R.N, dan Kell, W.G. “Modern Auditing”. Edisi Ketujuh. Jilid 1. Jakarta : Erlangga. 2006.

Brazel, Joseph F dkk. "Improving Fraud Detection: Do Auditor React to Abnormal Inconsistencecies between Financial and Nonfinancial Measures". 2010.

Darmoko, HW. "Profesionalisme Auditor KAP Dilihat dari Perbedaan Gender, Tipe KAP, dan Hirarki Jabatannya". Jurnal Sosial (September). Madiun. 2004.

Darwito. "Pengaruh Keahlian Auditor Terhadap Pemeriksaan Kecurangan (Fraud Auditing) dan Opini Audit dengan Independensi Sebagai Variabel Intervening”. Jurnal Ilmiah Bidang Akuntansi dan Manajemen (September). Hal 169-193.

Dewan Standar Profesional Akuntan Publik Ikatan Indonesia. "Standar Profesional Akuntan Publik Per 1 Januari 2009”. Jakarta : Salemba Empat.2001.

Effendi, M.Arief. "Tanggung Jawab Auditor Internal dalam Pencegahan, Pendeteksian dan Penginvestigasian Kecurangan”. 2008.

Ghozali, Imam. “Aplikasi Analisis Multivariate dengan Program SPSS”. Edisi Keempat. Semarang : Badan Penerbit UNDIP. 2009.

Gusnardi. "Pengaruh Peran Komite Audit, Pengendalian Internal dan Audit Internal Terhadap Pelaksanaan Good Corporate Governance dan Pencegahan Fraud”.2006.Tesis.

Hamid, Abdul. "Pedoman Penulisan Skripsi Fakultas Ekonomi dan Ilmu Sosial Universitas Islam Negeri Syarif Hidayatullah”. Jakarta. 2007.

Hastuti, Theresia Dewi, Stefani Lily Indarto dan Clara Susilawati. "Hubungan antara Profesionalisme Auditor dengan pertimbangan Tingkat Materialitas dalam Proses Pengauditan Laporan Keuangan”. Simposium Nasional Akuntansi VI. Surabaya. 2003.

Herty Safitri Yunintasari 2010 Pengaruh Independensi Dan Profesionalisme Auditor Internal Dalam Upaya Mencegah Dan Mendeteksi Terjadinya Fraud, Ejournal Skripsi Universitas Islam Negeri Syarif Hidayatullah Jakarta

Ikatan Akuntan Indonesia. "Standar Akuntansi Keuangan”. Jakarta: Salemba Empat.2009. Indriantoro, Nur. “Metodologi Penelitian Bisnis untuk Akuntansi \& Manajemen”. Yogyakarta. 2002.

Iqbal, Mohamad. "Peran dan Tanggung Jawab Internal Auditor dalam Mendeteksi Kecurangan". Percikan. Vol.43 (Agustus) Hal: 55-62.2003.

Kalbers, Lawrence P. dan Fogarty Timothi J. "Profesionalism and Its Consequences: A Study of Internal Auditors, Auditing: A Journal of Practice and Theory”. 1995.

Meutia, Inten. "Pengaruh Independensi Auditor Terhadap Manajemen Laba untuk KAP Big 5 dan Non Big 5". Jurnal Riset Akuntansi Indonesia (September). 2004.

Mulyadi. "Pemeriksaan Akuntansi". STIE YKPN. Yogyakarta. 2006. Nurjannah. "Pengaruh Peran Auditor Internal Pelaksanaan Independensi Auditor, Profesionalisme Auditor, Manajemen Laba Terhadap dengan Tekanan Peran (Pola Stres)'”.2008.

Prasetyo, Priyono. "Fraud: Tanggung Jawab Auditor Independen serta Dampak Terhadap Profesi Auditor”. Kajian Bisnis No.26 (Mei-Agustus).2002.

Ramaraya, Tri. "Pendeteksian Kecurangan (Fraud) Laporan Keuangan oleh Auditor Eksternal”. Jurnal Akuntansi dan Keuangan, Vol. 10, No. 1 (hal. 23-33). Mei 2008.

Sarah Trijayanti, Siti. "Pengaruh Peran dan Tanggung jawab Auditor Internal Terhadap Pencegahan Tindakan Kecurangan (Fraud)”.2008.Skripsi.

Sulistiyowati, Firma. "Peran Fraud Auditor dalam Mendeteksi Fraud untuk Mewujudkan Good Governance dan Good Corporate Governance di Indonesia”.Jurnal Akuntansi dan Keuangan Sektor Publik.Vol.04,No.10 (Februari) Hal: 13-24.2003

Sawyer, B, Lawrence. Dittenhofer A, Mortimer., dan Scheiner H, James. “Internal Auditing”. Buku 1. Jakarta: Salemba Empat.2006. 
Setiawan, Wawan. “Fraud: Suatu Tinjauan Teoritis". Kompak No.7 (Januari- April) : 137-153. 2003. Silvesterstone, Howard dan Michael Sheetz. "Forensic Accounting and Fraud Auditing for NonExsperts".USA.2007

Simanjuntak, Ridwan. "Kecurangan : Pengertian dan Pencegahan”. Jakarta. 2009. Sodik, Muhammad. "Pengaruh Keahlian dan Independensi Audit Internal Terhadap Kemampuan Mendeteksi Indikasi Fraud”. 2007.

Taufik, Muhammad. "Pengaruh Pengalaman Kerja dan Pendidikan Profesi Auditor Internal Terhadap Kemampuan Mendeteksi Kecurangan (Fraud)”. 2008.Skripsi.

Tuannakota, Theodorus M. "Akuntansi Forensik dan Audit Investigatif”. Seri Departemen Akuntansi. Jakarta: LP-FEUI. 2007.

Tugiman, Hiro. "Standar Profesional Audit Internal”. Yogyakarta: Kanisius. 2006.

Wahyudi, Hendro. "Pengaruh Profesionalisme Auditor Terhadap Tingkat Materialitas Dalam Pemeriksaan Laporan Keuangan”. Simposium Nasional Akuntansi IX. Padang. 2006.

Widjaja Tunggal, Amin. “Internal Auditing (Suatu Pengantar)”. Jakarta: Havarindo. 2009.

Widjaja Tunggal, Amin. "Pokok-pokok Audit Kecurangan”. Jakarta: Harvarindo. 2009.

Winarna, Jaka. "Independensi Auditor : Suatu Tantangan Masa Depan”. Jurnal Akuntansi dan Bisnis (Agustus). Hal 178-186.

Wurangian, Hanny dan Muslich Anshori. "Pengaruh Faktor Internal dan Faktor Eksternal Terhadap Independensi Auditor". Ekuitas.

Surabaya. 2003. Yuniarti, Emylia dan Eti. "Pendeteksian Kecurangan Akuntansi dan Dampaknya Terhadap Profesi Akuntan”. Akuntabilitas: Jurnal Penelitian dan Pengembangan Akuntansi. 2008. 